\title{
Innovative Design Strategy Based on Customer Requirements
}

\author{
Chen Wang, Wu Zhao ${ }^{*}$, Zhiyong Wang, Kai Zhang, Xiaolong Li, and Xin Guo
}

School of Manufacturing Science and Engineering, Sichuan University, Chengdu 610065, China

\begin{abstract}
Enterprises face increasing challenge in the designing stage which needs to turn the customer's needs into technical characteristics. In order to enhance the competitiveness of products, a demand-oriented innovative design model was proposed. This model integrates user demand accessing, technology feature mapping, quality function deployment and innovative solutions generation. During the design stage, designers need to match the acquired customer requirements to corresponding technical features, then apply House of Quality (HOQ) for building the mapping of user requirements to the technical features, analyzing the correlation and weights, and then with the aid of the theory of inventive problem solving (TRIZ) to resolve corresponding technical contradictions. Finally, an innovative solution of car steering demonstrated the feasibility of the demand-oriented innovative design model.
\end{abstract}

Keywords: Innovative design, QFD, technical characteristics, TRIZ, user requirements.

\section{INTRODUCTION}

In order to adapt to the rapidly changing market environment, responding to market demand quickly and developing innovative products have significance for enterprises [1].

In order to improve competitiveness of product, enterprises pay more and more attention to the requirements analysis tools and innovative design theory [2]. However, analyzing requirements and applying innovative design method in isolation cannot meet the demand of complex product design, there is an urgent need to establish a systematic strategy of product innovative design. A series of product innovation design process model based on the FBS and conceptual level are proposed by American professor Nigel Cross, professor Jorma and Australia Gero et al. [3]. Product conceptual design process model based on TRIZ/QFD/FA is proposed by Ma Huaiyu, Ming-chen meng of Tsinghua University [4]. A design method combining the product conflict resolution process based on TRIZ and TOC are proposed by Yuan Cai Yun of Hebei University of technology, Run-hua Tan [5]. These innovation design model, however, focuses on building design process and solving technical problems, pays less attention to the user's needs. For this reason, researching on the demand oriented product innovation design has important implications for improving the competitiveness product.

\section{DEMAND ORIENTED PRODUCT INNOVATIVE DESIGN}

The demand oriented product innovative design strategy involves decision-making method and the acquisition method of technical characteristics, and the theory of TRIZ.

\subsection{The Acquisition of User Requirements and Technical Characteristics}

Firstly, it is needed to acquire the customer demand with the help of 5W2H method, and apply Analytic Hierarchy Process (AHP) to classify the expression of the user demand. To establish a relationship between user requirements and the technical features, it is needed to get the technical features. There are several common methods of obtaining technical features, such as: brainstorming, the library of engineering characteristics, practical experience and technical documentation, etc.

\subsection{The Mapping of User Requirements to the Technical Characteristics}

Designers need to understand the user requirements comprehensively, then acquire the technical features accordingly [6]. Once the requirements and technical features are accessed, engineers need to figure out the corresponding relation. The basic idea of mapping is that user requirements translate into technical characteristics which can be used in the design process by engineers. Quality Function Deployment (QFD), mapping relation matrix of requirements and technical characteristics by building house of quality (HOQ) [7]. Applying the Delphi method to quantify the relationship between technology characteristics and user requirement, which involves organizing a number of experts to score evaluation index independently and using statistical methods to obtain the judgment [8].

\subsection{Problem Solving Strategy}

HOQ tools can reflect the problems in the design process, but can't deal with it. Therefore, there is need to introduce innovative ways to solve these problems.

The matrix of HOQ determine the negative correlation between the technical characteristics, which is the 
contradiction encountered in product design process. Design process also means solving these contradictions creatively [10]. This process is in line with the core idea of Theory of Inventive Problem Solving (TRIZ), TRIZ is a theory which can effectively solve technological conflicts with creative ideas. TRIZ is "a problem-solving, analysis and forecasting tool derived from the study of patterns of invention in the global patent literature" [9]. The theory developed on a foundation of extensive research covering hundreds of thousands of inventions across many different fields to produce a theory which defines generalizable patterns in the nature of inventive solutions and the distinguishing characteristics of the problems that these inventions have overcome.

The theory includes a practical methodology, tool sets, a knowledge base, and model-based technology for generating new ideas and solutions for problem solving. It is intended for application in problem formulation, system analysis, failure analysis, and patterns of system evolution.

There are three primary findings of this research. The first is that problems and solutions are repeated across industries and sciences, the second that patterns of technical evolution are also repeated across industries and sciences, and the third and final primary finding is that the innovations used scientific effects outside the field in which they were developed. In the application of TRIZ all these findings are applied to create and to improve products, services, and systems [10]. There are lots of conflicts in the process system, so it is appropriate to apply TRIZ into process innovation design.

For the correlation information of technical features, the roof of HOQ can be divided into two parts [11]: region A and region $\mathrm{B}$, according to the difference of negative correlation technical characteristics. Area A represents the conflict between the two technical characteristics, and the area $\mathrm{B}$ represents the conflict of technique characteristics itself, these two types of conflict correspond to the physical conflicts and technical conflicts of TRIZ. The process of problem solving based on HOQ is shown in Fig. (1).

\section{CUSTOMER REQUIREMENTS ORIENTED PRODUCT INNOVATION DESIGN PROCESS MODEL}

Based on the study of customer requirements, technical characteristics and TRIZ innovation theory, the customerrequirements-oriented product innovation design process model is built. The design process model includes four sub models [12]: the customer requirements analysis model, technology characteristic analysis model, the model of quality function deployment (QFD) and design problem analysis and solving model, as shown in Fig. (2).

\subsection{Customer Requirements Analysis Model}

Customer requirements analysis model includes the acquisition of customer requirements, the organization of customer requirements, the sorting of the customer requirements importance and competitive analysis of market. First, the enterprises can obtain customer requirements by questionnaire, $5 \mathrm{H} 2 \mathrm{~W}$ and some other methods. Second, the information of customer requirements should be organized, which includes removing redundant requirements, formal expressions, classification. Finally, according to the operation procedure of $\mathrm{KJ}$ method, the customer requirements are categorized in layers and the weight indexes can be obtained by AHP.

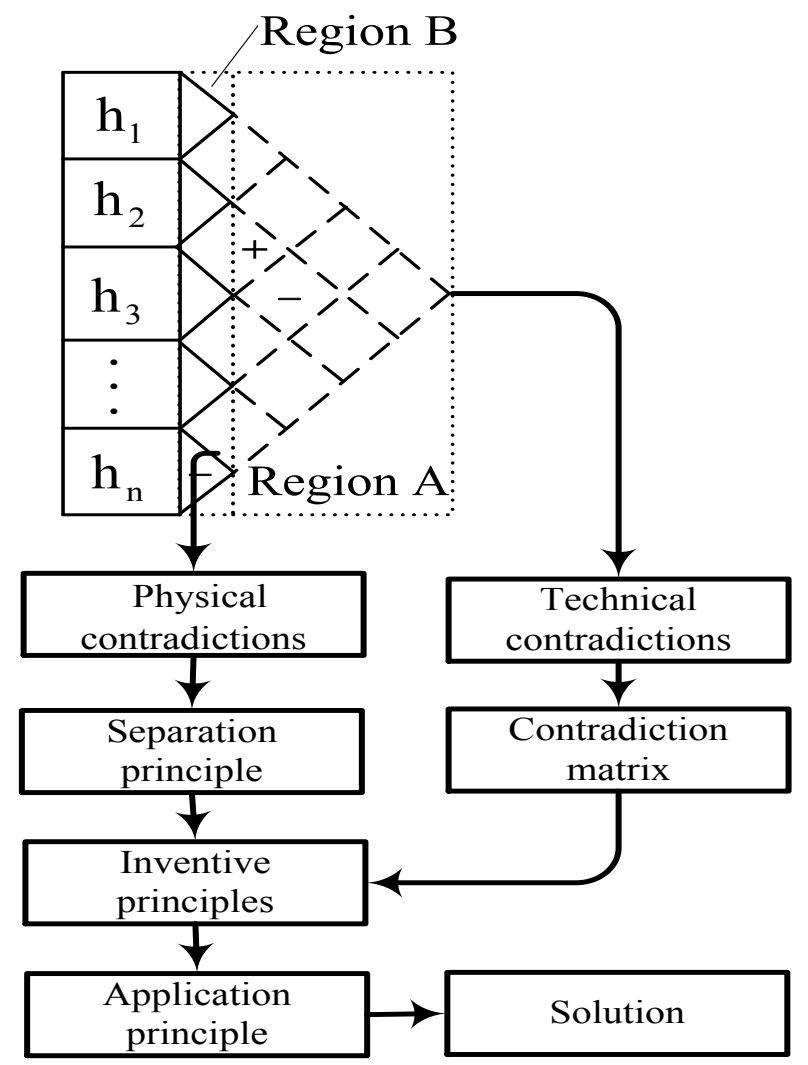

Fig. (1). The process of problem solving based on HOQ. 3.

\subsection{Technical Characteristic Analysis Model}

Technical characteristics analysis model established on the basis of the information obtained in the first model, which contains the acquisition of the technical characteristic, the organization of the technical characteristic and competitive analysis of technical characteristic [13]. First, according to the information of customer requirements, engineers collect technical characteristic which can satisfy the customer requirements by brainstorming method, technical characteristic database and quality factor table. Then, technical characteristics are organized in terms of the company's own scale and situation. Finally, the competitiveness of each technical characteristic in the market is determined.

\subsection{Model of Quality Function Deployment (QFD)}

Model of quality function deployment (QFD) establishes the connections between customer requirements and technical characteristic, which accelerates the speed of new product development [14]. The model contains the mapping from customer requirements to technical characteristic, the relationship matrix of customer requirements and technical characteristic, the sorting of the technical characteristics importance and the self-correlation of technical 
characteristics. First, according to the information obtained in the first and the second model, the customer requirements are mapped to technical characteristics, in which technical characteristics should be refined. Then, the correlation degrees are obtained by Delphi method. The final importance of technical characteristics is determined by taking into consideration the importance of customer requirements. Finally, the self-correlation between customer requirements and technical characteristic is analyzed [15]. 


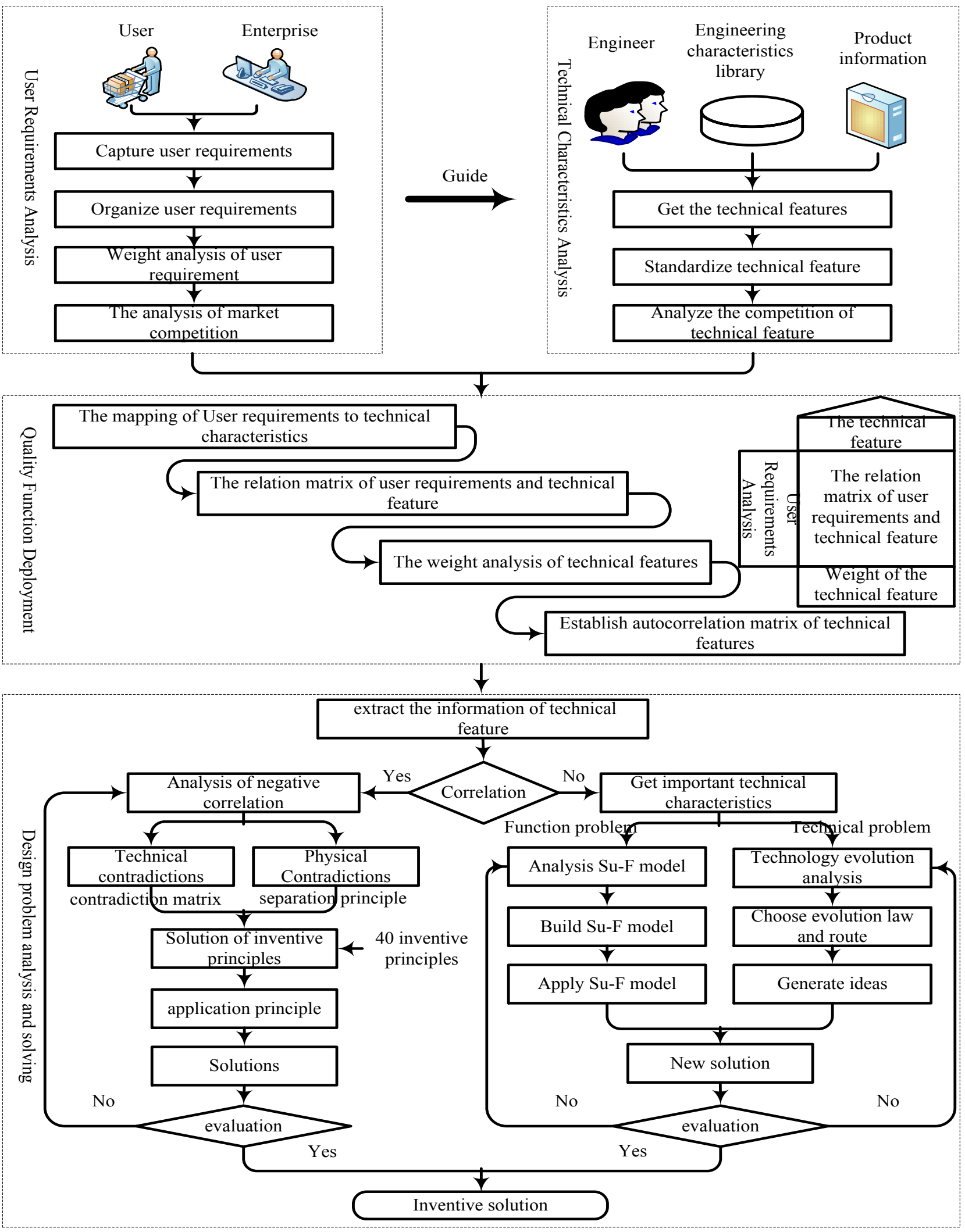

Fig. (2). Product innovation design model for customer requirements.

\subsection{Design Problem Analysis and Solving Model}


Design problem analysis and solving model contains the extraction of technical characteristics, correlation analysis, problem analysis and solution [16]. First, the technical characteristics which are negatively related to others or have high importance are extracted. Then, the technical characteristics which are negatively related to others the technical characteristics are analyzed whether they belongs to the technical and physical contradictions. The technical characteristics which have high importance are analyzed by substance-field analysis model or technology evolution theory. Finally, on the basis of the analysis, the innovative solutions can be obtained and applied to the product development process, so that the innovative product can satisfy the customer requirements.

\section{AUTOMOBILE REDIRECTOR DEMAND ANALYSIS}

\section{AND INNOVATIVE DESIGN}

\subsection{Automobile Redirector Design Task}

Automobile redirector requires good maneuverability and stability, and at the same time enable the transmission of road real-time situation to drivers to make correct decision [17]. In the example of the research and development of automobile redirector, using customer requirements as the guidance, QFD and TRIZ theory as the tools to make the innovative study on the steering gear for verifying the feasibility of the proposed method 4.2 redirector user demand requirements acquisition and processing

After classification of the customers' requirements for steering gear, utilize the analytic hierarchy process (AHP) to analyze the demand of information processing, single sorting

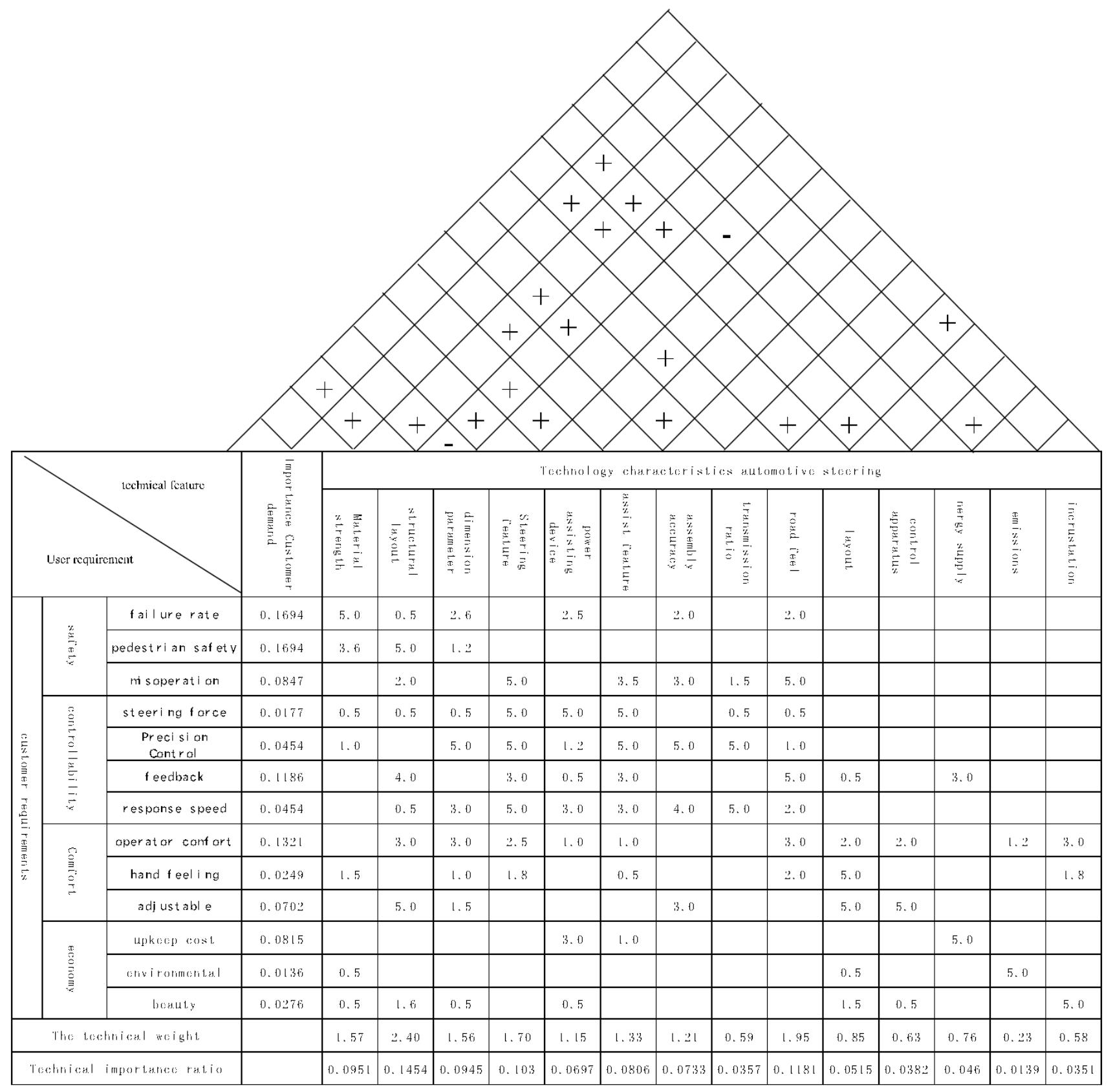

Fig. (3). The quality houses of automobile steering gear design. 


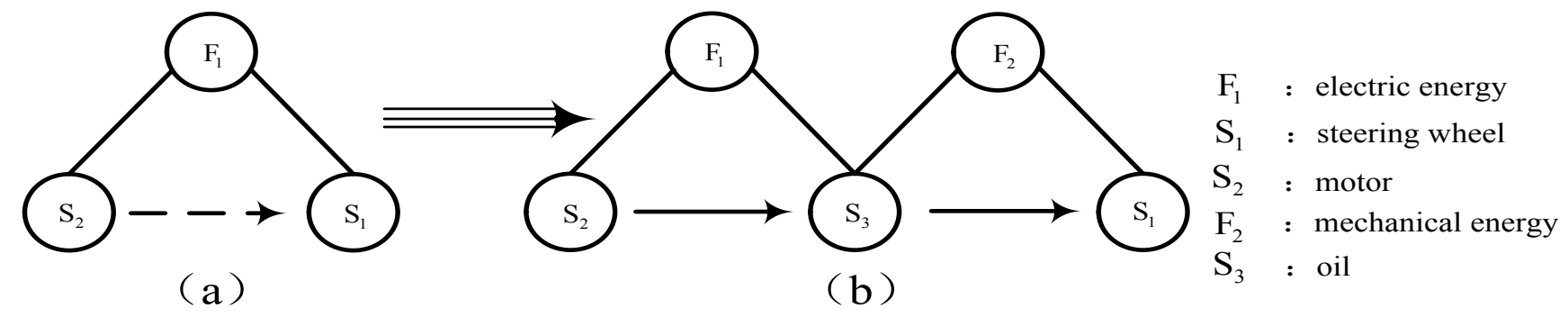

Fig. (4). Road sense to strengthen the TRIZ - field model.

result of the automobile redirector customer requirements levels can be obtained, and inspect the consistency of judgment matrix afterwards

\subsection{User Requirements to the Technical Characteristics of Mapping}

After obtaining the customer requirements, acquiring the corresponding technical features guided by customer requirements. Establish the $\mathrm{HOQ}$ at the design stage of automobile redirector, as shown in Fig. (3).

\subsection{Steering Problem Solving}

Automobile steering system problem belongs to the technical conflict, so it's especially suitable for using TRIZ theory creatively to solve the problem [18]. Use TRIZ evolution theory to analyze the technical characteristics of steering structure layout Analysis the structural layout according to "transmission route to the fluid or field" in the law of improving the ideal level and therefore find wire control steering layout is the ideal state of steering evolution technique. Wire control steering cancelled the mechanical connections between steering wheel and steering actuator, bring to electrical signals instead of mechanical transmission process, making the steering get greater freedom in structure design. Establishing its content - field model and using the new medium - hydraulic to make connection, which implement mechanical connections between actuator and steering wheel, and at the same time meet the requirement of structure layout [19]. Its improved model of physical-field is as shown in Fig. (4).

Combining with the technical feature on the basis of solving the problems encountered in the process of steering gear design to complete the overall design scheme of automobile redirector, its innovative solutions as shown in Fig. (5).

In this innovative solution, the movement of the tie rod will break the balance of the oil in the perception oil cylinder, produce a certain resistance for perception oil cylinder and then result in a way. When determining the design scheme of steering gear, design oil cylinder, road sense perception oil cylinder and hydraulic circuits according to the design requirements and general knowledge of steering, establish the redirector virtual prototype afterwards, as shown in Fig. (6).

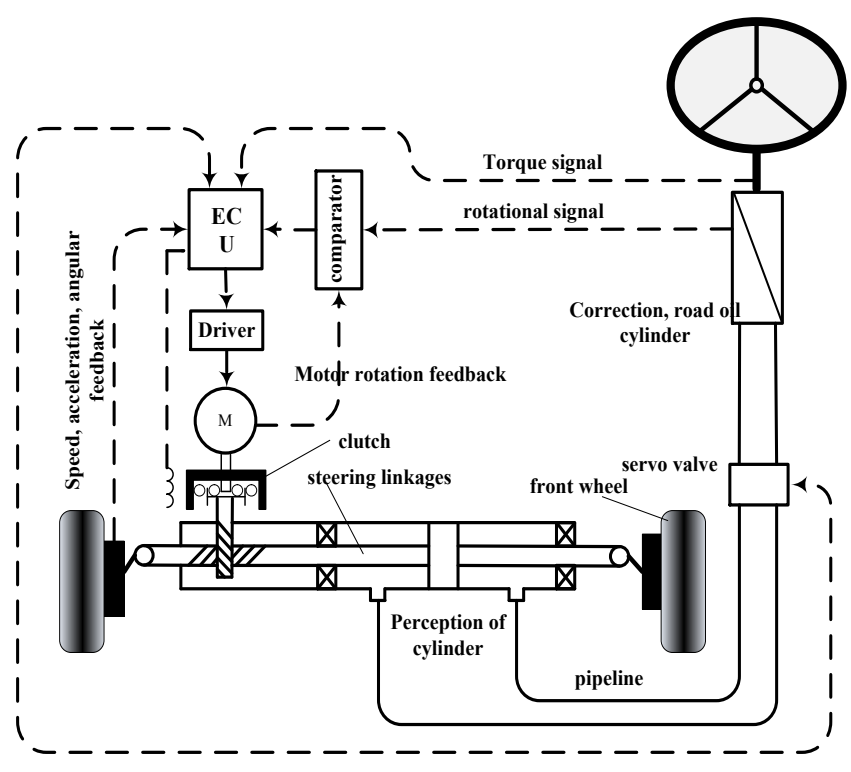

Fig. (5). Automobile redirector innovative solutions.

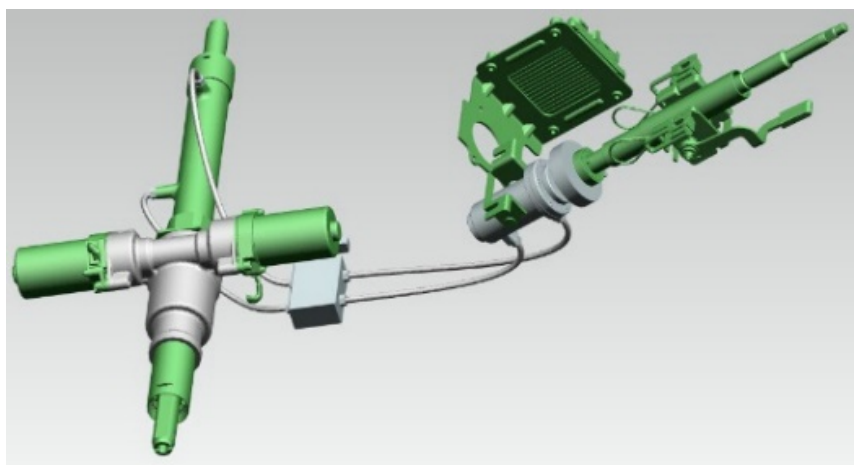

Fig. (6). Automobile redirector three-dimensional model.

\section{CONCLUSION}

This paper studies the customer requirements access and technical characteristics access, the importance of their mapping relation and technical features, uses the TRIZ innovation methods targeted to solve the problem, therefore build the product innovation design model facing up to customer requirements. Using the design and development of automobile redirector as an example in the end to verify the feasibility of the model. However, the operability is poor when confront the diversity technical feature, further research is needed. 


\section{CONFLICT OF INTEREST}

The authors declare that there is no conflict of interests regarding the publication of this paper.

\section{ACKNOWLEDGEMENT}

This work was supported in part by Natural Science Foundation of China (No. 51175357\&No.51435011), and Special Program for Key Basic Research of the Ministry of Science and Technology, China (Grant No. 2013IM030500). Gratitude is also extended to the reviewers and the Editor for their valuable comments.

\section{REFERENCES}

[1] Y. M. Wang, and K. S. Chin, "Technical importance ratings in fuzzy QFD by integrating fuzzy normalization and fuzzy weighted average", Computers \& Mathematics with Applications, 62(11), pp. 4207-4221, 2011.

[2] Y. Akao, "Quality function deployment: integrating customer requirements into product design", London: Productivity Press, 2004.

[3] Al'Tshuller, G. S., The innovation algorithm: TRIZ, systematic innovation and technical creativity, Technical Innovation Center, Inc. 1999.

[4] A. Herrmann, F. Huber, and C. Braunstein, "Market-driven product and service design: Bridging the gap between customer needs, quality management, and customer satisfaction", International Journal of Production Economics, vol. 66, no. 1, pp. 77-96, 2000.

[5] Y. Du, H. Cao, X. Chen, and B. Wang, "Reuse-oriented redesign method of used products based on axiomatic design theory and QFD”, Journal of Cleaner Production, vol. 39, pp. 79-86, 2013.

[6] J. A. Carnevalli, P. A. C. Miguel, and F. A. Calarge, "Axiomatic design application for minimising the difficulties of QFD usage", International Journal of Production Economics, vol. 125, no. 1, 1$12,2010$.

[7] C. Yeh, J. C. Huang, and C. Yu, "Integration of four-phase QFD and TRIZ in product R\&D: a notebook case study", Research in Engineering Design, vol. 22, no. 3, pp. 125-141, 2011.
[8] C. Tseng, C. Torng, and S. Lin, "Prioritization of product design tasks using QFD, TRIZ and DSM, In Industrial Engineering and Engineering Management (IE\&EM)", in IEEE 17Th International Conference on IEEE, 2010, pp. 871-875.

[9] L. K. Chan, and M. L. Wu, "Quality function deployment: a literature review", European Journal of Operational Research, vol. 143, no. 3, pp. 463-497, 2002.

[10] J. Dai, and J. Blackhurst, "A four-phase AHP-QFD approach for supplier assessment: a sustainability perspective", International Journal of Production Research, vol. 50, no. 5019, pp. 5474-5490, 2012.

[11] Y. Li, J. Tang, X. Luo, and J. Xu, "An integrated method of rough set, Kano's model and AHP for rating customer requirements' final importance", Expert Systems with Applications, vol. 36, no. 3, pp. 7045-7053, 2009.

[12] Y. L. Li, K. S. Chin, and X. G. Luo, "Determining the final priority ratings of customer requirements in product planning by MDBM

[13] and BSC", Expert Systems with Applications, vol. 39, no. 1, pp. 1243-1255, 2012.

[14] Y. Lin, H. P. Cheng, M. L. Tseng, and J. C. Tsai, "Using QFD and ANP to analyze the environmental production requirements in linguistic preferences", Expert Systems with Applications, vol. 37, no. 3, pp. 2186-2196, 2010.

[15] Y. Li, J. Wang, X. Li, and W. Zhao, "Design creativity in product innovation", The International Journal of Advanced Manufacturing Technology, vol. 33, no. 3-4, pp. 213-222, 2007.

[16] X. Lai, M. Xie, K. C. Tan, and B. Yang, "Ranking of customer requirements in a competitive environment", Computers \& Industrial Engineering, vol. 54, no. 2, pp. 202-214, 2008.

[17] C. Y. Zhu, M. S. Yang, X. Q. Gao, and X. C. Yang, "Modifying the Importance Ratings of Customer Requirements Based on DEMATEL and Entropy", Industrial Engineering and Management, vol. 3, pp. 018, 2012.

[18] E. Q. Wang, S. H. Yu, and H. M. Du, "Application of QFD and information entropy in improved design for the tank truck", Machinery Design \& Manufacture, vol. 8, pp. 024, 2011.

[19] D. Mcdonagh, A. Bruseberg, and C. Haslam, "Visual product evaluation: exploring users' emotional relationships with products", Applied Ergonomics, vol. 33, no. 3, pp. 231-240, 2002.

[20] P. Desmet, R. Porcelijn, and M. Van Dijk, "Emotional Design, Application of a research-based design approach", Knowledge, Technology \& Policy, vol. 20, no. 3, pp. 141-155, 2007. 